\title{
Psikolojik Sermaye ile Çalışan Sesliliği Arasındaki İlişkide Algılanan Stresin Aracılık Rolü: Hizmet Sektöründe Bir Araştırma
}

\author{
DOI: $10.26466 /$ opus. 835768 \\ * \\ Sümeyra Ceyhan* - Olcay Okun** \\ * Öğr. Gör. Dr., Bingöl Üniversitesi, Bingöl/Türkiye \\ E-Posta: sceyhan@bingol.edu.tr \\ ORCID: $\underline{0000-0001-5436-2996}$ \\ ** Dr.,Milli Savunma Bakanlığı, Ankara /Türkiye \\ E-Posta: olcayokun@yahoo.com.tr \\ ORCID: $\underline{0000-0002-7096-5794}$
}

\section{Öz}

Çalışanların pozitif psikolojik kaynaklarının iş yaşamındaki olumlu sonuçlara etkisi ve bu kaynakların beslenerek geliştirilmesi, güçlenen ve daha olumlu yaklaşımlar gösteren çalışanlara doğru evrilmektedir. Psikolojik sermaye bireylerin olumlu ve pozitif yönlerinin geliştirilmesine, pozitif deneyimler yaşamalarına ve streslerini azaltıcı unsurlardan biridir. Ancak stres fiziksel, davranışsal veya psikolojik pek çok olumsuz sonuç ile iş yaşamında ilişkilendirilmektedir. Yapıcı düşüncelerin dile getirilmesi şeklinde ifade edilen çalışan sesliliği bilişsel bir maliyet ve fayda hesabından kaynaklanmaktadır. Bu noktada çalışmanın amacl, emek-yoğun otel işletmelerinde çalışanların psikolojik sermaye düzeylerinin ve algzladıkları stres düzeyinin, çalı̧̧an sesliliğine olan etkisini ölçmektir. Çalışmada bilimsel araştırma yöntemi olarak birincil veri toplama tekniklerinden faydalanılmış olup araştırmanın evrenini Van ilinde faaliyet gösteren otel çalışanlar oluşturmaktadır. Elde edilen verilerin test edilmesi amactyla PLS-SEM yöntemi ve SPSS 22.0 istatistiki analiz yazılımı kullanılmıştır. Elde edilen bulgulara göre psikolojik sermaye algzlanan stresi negatif ve çalışan sesliliğini pozitif yönlü ve anlamlı olarak etkilediği görülmektedir. Aynı zamanda algılanan stres çalışan sesliliğini negatif yönlü ve anlamlı olarak etkilemektedir. Ayrıca algılanan stresin, psikolojik sermayenin çalş̧an sesliliği üzerindeki etkisinde aracı rol oynadığ̆ da test edilmiştir. Bu bağlamda çalışma kapsamında elde edilen bulguların literatürdeki eksikliğin giderilmesine katkı sağlayacağı aynı zamanda araştırmacılara yönelik yararlı bilgiler sunması hedeflenmektedir.

Anahtar Kelimeler: Algılanan stres, Psikolojik sermaye, Çalışan Sesliliği. 


\title{
The Mediating Role of Perceived Stress in the Relationship Between Psychological Capital and Employee Voice: A Research in the Service Sector
}

*

\begin{abstract}
The effect of positive psychological resources of employees on positive results in business life and the development of these resources through nutrition are evolving towards employees who are strengthened and who Show more positive approaches. Psychological capital is one of the factors to improve the positive and positive aspects of individuals, to have positive experiences and to reduce their stress. However, stress is associated with many physical, behavioral or psychological negative consequences in business life. Employee voice, expressed as expressing constructive thoughts, stems from a cognitive cost and benefit calculation. At this point, the aim of the study is to measure the effect of psychological capital levels and perceived stress levels of employees in labor-intensive hotel enterprises on employee voiceover. In the study, primary data collection techniques were used as a scientific research method, and the universe of the study is composed of hotel staff operating in the province of Van. PLS-SEM method and SPSS 22.0 statistical analysis software were used to test the data obtained. According to the findings, it is seen that psychological capital affects perceived stress negatively and employee vocal positively and significantly. At the same time, perceived stress negatively and significantly affects employee vocalism. It has also been tested that perceived stress plays a mediating role in the effect of psychological capital on employee voices. In this context, it is aimed that the findings obtained within the scope of the study will contribute to the gap in the literature and at the same time provide useful information for researchers.
\end{abstract}

Keywords: Perceived stress, employee voice, psychological capital. 


\section{Giriş}

Yöneticiler iş yerinde düzeltici önlemler alabilmeleri, işleyişlerini geliştirebilmeleri ve daha etkili stratejik kararlar alabilmeleri için çalışanlarının sorunlarını ve fikirlerini öğrenmek isterler (Burris vd.,2017). Bilgi, fikir, öneri, hatta eleştiri şeklinde olan çalışan katkısı organizasyonlar için önemli ve değerli bir kaynaktır. Çalışanların iyileştirme konusundaki fikir ve önerilerini dile getirmeleri örgütsel işleyişin geliştirilmesinde kritik bir rol oynayabilir (Şahin, 2013). Bu bağlamda çalışanın seslilik davranışını göstermesini teşvik eden veya engelleyen faktörler pek çok çalışmaya konu olmuş ve çalışan sesliliğinin güçlendirilmesi için pek çok öneri sunulmuştur (Allen vd., 2015; Gunawardana, 2014; Adelman, 2012).

Bazı çalışmalarda çalışan sesini destekleyen, çalışanların daha fazla konuşma ve harekete geçmesini destekleyebilecek yönetsel iyileştirilmeler araştırılmış ve yöneticilere öneriler sunulmuştur (Haskins ve Freeman, 2015; Detert ve Burris, 2007). Yazında yer alan bir kısım çalışmada (Şahin, 2013; Vakola ve Bouradas, 2005) organizasyonel faktörler (örgütsel destek, örgütsel kültür, örgütsel iklim, organizasyon şeması, vb), bir kısım çalışmada ise çalışan karakteristiklerinin sese olan etkisi (LePine ve Van Dyne, 2001) incelenmiştir. Çalışan sesliliği organizasyonların gelişmeleri ve eksiklerini gidermeleri bağlamında eşsiz bir bilgi kaynağı olmasına karşın doğası ve ana bileşenleri hakkında halen çok az deneysel kanıt vardır.

Çalışmaya konu edilen otel işletmeleri yoğun rekabet ortamında birbirleri ile yarışan, emek-yoğun özelliğe sahiptir. Hizmet sektörünün belki de en hata kaldırmayan ve insan faktörü üzerinde dönen bir alanı olan otel işletmelerinde, çalışanlar işletmede bulunduğu süre oranında tecrübe ve bilgi birikimini artırmaktadır. Bu bağlamda sahip olunan insan kaynağ1 ve niteliği rekabet üstünlügü kazanmada temel unsur olarak değerlendirilmektedir (Met ve Erdem, 2006; Akçadağ ve Özdemir, 2005). Psikolojik sermayenin ölçülebilir ve geliştirilebilir özelliği otel çalışanlarında işlerine karşı pozitif tutum ve davranışlar geliştirilmesi bağlamında eşsiz fırsatlar sunmaktadır. Çalışmada elde edilecek bilgiler çalışan sesliliği doğasını etkileyen pozitif psikolojik kaynakları ve stresin etkilerine 1şık tutmayı amaçlamaktadır. 


\section{Kavramsal Çerçeve}

Bu bölümde çalışmanın değişkenlerini oluşturan psikolojik sermaye kavramı, boyutları, algılanan stres ve çalışan sesliliği kavramları ele alınmıştır. Aynı zamanda bu bölümde ilgili değişkenlerin birbirleri ile ilişkilerini elen teori ve hipotezler sunulmuştur.

\section{Psikolojik Sermaye}

Adam Smith (2005) insan sermayesini tüm sakinlerin veya toplum üyelerinin kazanılmış ve faydalı yetenekleri olarak tanımlar. Bu yeteneklerin edinilmesi, eğitim, çalışma veya çıraklık sırasında bir maliyet gerçekleştiğinden, söz konusu yetenekler servetinin bir parçası, aynı zamanda ait oldukları toplumun da sermayesinin bir parçasıdır. Bu fikrin başlıca modern gelişmeleri, insan sermayesinin bir bireyi daha fazla işgücü verimliliğine yönlendiren bilgi, beceri ve yetkinliklerden oluştuğunu belirten Mincer (1958) ve Becker (1964) tarafından başlatılmıştır (Kell vd., 2018). İnsan sermayesinin yeni kuşak tanımlarından biri olan psikolojik sermaye, Seligman ve Csikszentmihalyi (2000) tarafından bir akım haline getirilen pozitif psikoloji yaklaşımının örgütsel davranış çalışma alanında karşılı̆̆ 1 olarak konumlandırılmaktadır.

Psikolojik sermaye, bireyin pozitif psikolojik kapasiteleri (öz-yeterlik, umut, iyimserlik ve psikolojik dayanıklılık) ile ifade edilen, söz konusu kapasitelerin birikmesi, ölçülmesi, artırılması ve geliştirilmesi ile bireyin günlük yaşamında, iş yaşamında, sosyal ve aile ilişkilerinde pozitife doğru gidişi temsil eden, gelişimi devam eden ve potansiyel kapasiteleri üzerinde çalışılan pozitif insan kaynağı sermayesidir (Okun, 2017; Luthans, 2012; Luthans vd., 2007a). Bu bağlamda psikolojik sermaye boyutları olan öz-yeterlik, umut, iyimserlik ve psikolojik dayanıklılık açısından ele alınmaktadır. Buna göre öz yeterlilik, çalışanın belirli bir görevi başarıyla yürüterek yerine getirmesi için ihtiyaç duyduğu motivasyonu, gerekli hareket yöntemlerini ve bilişsel kaynakları harekete geçirme konusundaki kabiliyetleri veya güvenleri olarak tanımlanır. Öz yeterlilik, başarı için esastır (Bandura, 1997). Umut, hedefe yönelik yolları belirleme (agency) ve hedeflere ulaşma yollarını (pathways) planlama ve kendini motive etme olarak tanımlanmaktadır (Snyder, 2000). İyimserlik, gelecekte iyi 
şeylerin olacağına olan inançtan ziyade, gerçekleşen olayların sebebini pozitif nedenlere dayandırarak açıklama biçimidir. Psikolojik sermaye bileşeni olarak iyimserliği diğer iyimserlik tanımlarından ayıran temel farklılık budur (Luthans vd., 2007a). Psikolojik dayanıklılık, başarısızlık, zorluklar, çatışma, sıkıntı, belirsizlik hatta olumlu değişim, ilerleme ve artan sorumluluktan "geri dönme" psikolojik kapasitesi olarak tanımlanmaktadir (Luthans, 2002).

Psikolojik sermaye sinerjik bir etki ile dört bileşeninden daha fazla etki gösteren çekirdek bir yapıdır ve çalışanın iş yerinde gösterdiği pek çok olumlu tutum ile ilişkili olduğu daha önce yapılan yurtiçi ve yurtdışı pek çok çalışmada ortaya koyulmuştur (Avey , 2008; Sameer vd., 2019; Erkuş ve Findiklı, 2013).

\section{Algilanan Stres}

Algılanan stres, bir bireyin taleplerinin başa çıkma kabiliyetlerini aştığını algılamasıdır Algılanan stresin fazla olmasının iş, aile, okul ve sosyal hayata pek çok olumsuz yansımaları mevcuttur. Algılanan stres bu nedenle yönetimsel tedbirler alınması bakımından önemli bir müdahale hedefidir (Adams vd., 2016). Algılanan stres, nesnel stresli olayların, başa çıkma süreçlerinin, kişilik faktörlerinin bir fonksiyonu olarak tecrübe edilen stres seviyesini ölçen bir sonuç değişkeni olarak görülebilir (Cohen vd., 1983). Bu sayede çalışmada, çalışanların psikolojik sermaye düzeylerinin etkisini ölçmeye yardımcı olur.

\section{Çalışan Sesliliği}

Yüksek kaliteli kararlar almak ve dinamik iş ortamlarına başarılı bir şekilde uyum sağlamak için yöneticiler, çalışanlarının örgütsel sağlığını ve işleyişini sürdürmek için girdilerine giderek daha fazla güvenmektedirler (Li vd., 2018). Organizasyonlarda değişim ve gelişimin en önemli dinamiklerinden bir tanesi çalışanların seslilik davranışı göstermesi olarak ifade edilebilir. Temel olarak seslilik, çalışanların fikirlerini ilerletme ve göz önünde bulundurma fırsatına sahip olarak örgütsel kararların sonuçlarını etkileme becerisiyle ilgilidir (Farndale vd., 2011). Çalışan sesliliği, 
örgütsel veya birim işleyişini geliştirmek amacıyla işle ilgili konularda fikirlerin, önerilerin, kaygıların veya işlerle ilgili görüşlerin isteğe bağlı olarak iletilmesi olarak tanımlanır. Çalışan sesliliği, iyileştirme ve olumlu değişim sağlama amacı olan isteğe bağlı ve esasen yapıcı bir davranıştır (Morrison, 2011).

\section{Araştırma Modeli ve Hipotezleri}

Hobfoll (1989)'un Kaynakların Korunması Modelinin temel prensibi, bireylerin kaynakları korumak, geliştirmek ve inşa etmek için çaba göstermeleri ve bu değerli kaynakların potansiyel veya fiili kaybına tepki vermeleridir. Kaynaklar, bireyler tarafından değer verilen veya bu nesnelere, kişisel özelliklere, koşullara veya enerjilere erişmenin bir aracı olarak hizmet eden nesneler, kişisel özellikler, koşullar veya enerjiler olarak tanımlanır. Çevresel koşullar genellikle insanların kaynaklarını tüketmesini tehdit eder veya tüketmesine sebep olur. Söz konusu koşullar bireylerin statüsünü, pozisyonunu, ekonomik istikrarını, sevdiklerini, temel inançlarını veya özgüvenini tehdit edebilir. Kaynakların korunması modeline göre bireyin kaynaklarında hem algılanan hem de fiili kayıp veya kazanç eksikliği, stres üretmek için yeterli olarak öngörülmektedir.

Çalışanların ne hissettiğini söylemesini engelleyen durumlar mevcuttur. Ya da çalışanların bildiğini söylemesini sık sık engelleyen içinde bulunduğu organizasyona ait güçlü normlar ve savunma rutinleridir. Bunlar seslilik ile birlikte yaşanabilecek muhtemel örgütsel değişim esnasında olası iş kaybı korkusu, yönetici ve ekip üyelerinin çalışanın fikirleri karşısında ne düşünecekleri hakkındaki belirsizlik, durum kontrolü kaybı gibi birçok uyum sorunu çalışan sesliliğinin önündeki en büyük engeldir (Morrison ve Milliken, 2000; Vakola ve Bouradas, 2005; Haskins ve Freeman, 2015). Çalışanlar fikirlerini, düşüncelerini açıkça ifade edemedikleri zaman bu durum çalışanlar arasında stres, sinizm, memnuniyetsizlik ve işten ayrılmalara sebep olmaktadır (Beer ve Eisenstat, 2000).

Çalışanın kendini yetersiz görmesi, kendine olan güven eksikliği gibi pozitif psikolojik kaynaklarının yetersiz olmasının seslilik davranışı göstermesine engel olacağı düşünülmektedir. Aynı zamanda çalışanların pozitif psikolojik kaynaklarının geliştirilmesi ile algılanan stresin azalacağ ve seslilik davranışının artacağı değerlendirilmektedir. Bahsedilen teorik 
ve kavramsal çerçeve doğrultusunda, yapılan çalışmalarda psikolojik sermaye, algılana stres ve çalışan sesliliği değişkenlerinin tümünün tek bir araştırma modelinde incelenmediği görülmüş, Şekil-1 araştırma modeli kurularak aşağıda sunulan çalışma hipotezleri oluşturularak Van ilinde hizmet veren oteller örnekleminde test edilmiştir.

- Hipotez 1: Psikolojik sermaye algilanan stresi negatif yönlü ve anlaml olarak etkiler.

- Hipotez 2: Psikolojik sermaye çalışan sesliliğini pozitif yönlü ve anlamlı olarak etkiler.

- Hipotez 3: Algılanan stres çalışan sesliliğini negatif yönlü ve anlamlı olarak etkiler.

- Hipotez 4: Algllanan stres, psikolojik sermayenin çalışan sesliliği üzerindeki etkisinde aracı rolü oynar.

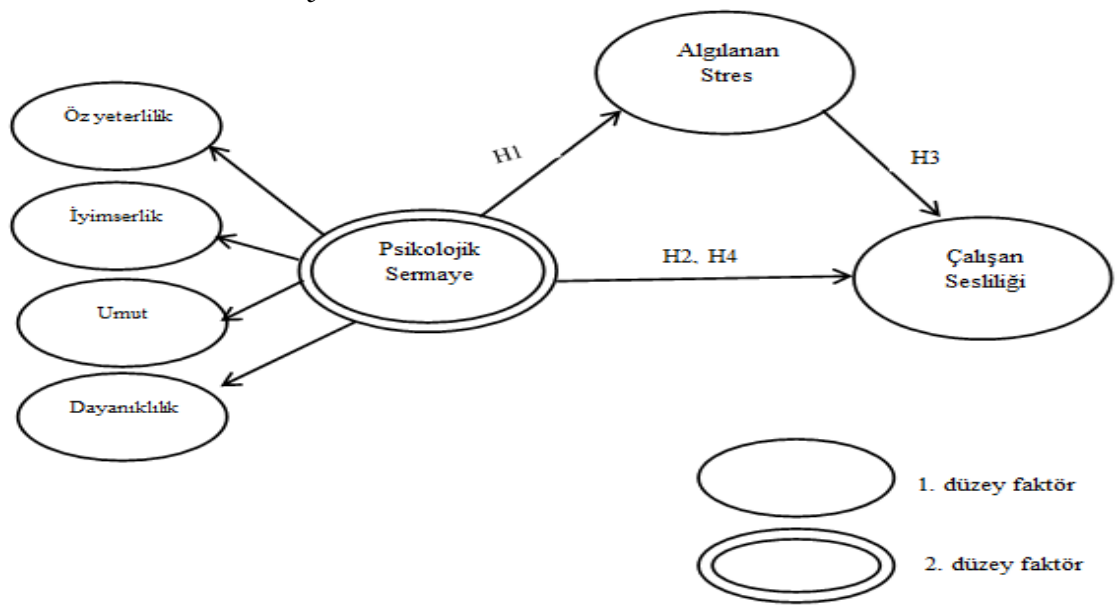

Şekil 1. Araştırmanın modeli

\section{Yöntem}

Araştırmanın bu bölümünde çalışmanın amacı ve öneminden, araştırmanın everen ve örnekleminden bahsedilmiştir. Aynı zamanda kullanılan veri toplama yöntemi, veri analizi ve bulgular yer almaktadır. 


\section{Araştırmanın Önemi ve Amacı}

Çalışmanın amacı, emek-yoğun otel işletmelerinde çalışanların psikolojik sermaye düzeylerinin ve algıladıkları stres düzeyinin, çalışan sesliliğine olan etkisini ölçmektir. Psikolojik sermaye, algılanan stres ve çalışan sesini destekleyen, çalışanların daha fazla konuşma ve harekete geçmesini destekleyebilecek yönetsel iyileştirilmeler araştırılmış ancak bu değişkenler arasındaki ilişkinin ele alındığı bir çalışmanın yapılmamış olması önem arz etmektedir. Araştırmanın psikolojik sermaye, algılanan stres ve çalışan sesliliği üzerinde düşünme ya da yeni araştırma imkanları sunacağı, organizasyonların gelişmeleri ve eksiklerini gidermeleri bağlamında bilgi kaynağ 1 sağlayacağı araştırma sonuçlarından umulmaktadır. Belirtilen amaçlara ulaşılmak için çalışma bir alan çalışması ile desteklenmiştir.

\section{Evren ve Örneklem}

Van ilince faaliyet gösteren tüm oteller ( 2 adet 5 yıldız, 4 adet 4 yıldız, 6 adet 3 yıldız ve 2 apart otel) araştırmaya dahil edilmiştir. Evrenin tamamına ulaşılarak, Şubat- Nisan 2018 tarihleri arasında ölçme aracı olarak kullanılan anket otel işletmelerinde çalışan toplam 247 personele uygulamış, 148 adet anket değerlendirmeye değer bulunarak analiz edilmiştir. $\mathrm{Bu}$ bağlamda toplanan veriler ve elde edilen verilerin geçerlilik veya güvenilirliği araştırma kullanılan yöntemin dönemi ve özellikleriyle sınırl1dır. Çalışma kapsamında kullanılan istatiksel analizin çalışmanın amacına uygun olacağı varsayılmaktadır.

\section{Araştırmanın Veri Toplama Yöntemi}

Çalışmada veri toplama aracı olarak birincil veri toplama tekniği olarak anket yönteminden faydalanılmıştır. Kullanılan anket formu literatürdeki farklı kaynaklardan elde edilen önermelerin derlenmesiyle oluşturulmuştur. Birinci bölümde kişisel bilgiler yer alırken ikinci bölümde psikolojik sermaye, üçüncü bölümde algılanan stres ölçeği ve dördüncü bölümde çalışan sesliliği ölçeği ile ilgili önermeler katılımcılara sunulmuştur. 
Anketin ikinci bölümünde kullanılan Luthans vd. (2007a) tarafından geliştirilen 24 maddeden oluşan Pozitif Psikolojik Sermaye Ölçeği Türkçeye Çetin ve Basım (2012) tarafından çevrilmiştir. Her biri 6 ifadeden oluşan ölçek; öz yeterlilik, iyimserlik, umut ve psikolojik dayanıklılık olmak üzere 4 boyuttan oluşmaktadır. Araştırmada söz konusu ölçek kullanılmıştır. Araştırma ölçeğinin uyum indeksleri sonucunda elde edilen veriler incelendiğinde: Ki-kare istatistiğinin serbestlik derecelerine oranı $(\chi 2 / \mathrm{sd})$ 2,107; yaklaşık hataların ortalama karekökü (RMSEA) 0,087; Tucker-Lewis indeksi (TLI) değeri 0,90, model iyilik uyum indeksi (GFI) 0,81 ve karş1laştırmalı uyum indeks (CFI) ise 0,91 olarak bulunmuştur. Bu bağlamda elde edilen bulgularda görüldüğü gibi ölçeğin iyi uyum değerlerine sahip olduğu görülmekte ve dolayısıyla iyi uyum göstermektedir.

Anketin üçüncü bölümünde Cohen, vd. (1983) tarafından geliştirilen İş Stresi Ölçeği kullanılmıştır. 5 maddeden ve tek boyuttan oluşan ölçek daha önce Küçükusta (2007) ve Turunç (2015) tarafından (dört madde olarak) konaklama işletmelerinde uygulanmıştır. Araştırma ölçeğinin uyum indeksleri incelendiğinde: Ki-kare istatistiğinin serbestlik derecelerine oranı ( $\chi 2 /$ sd) 2,253; yaklaşık hataların ortalama karekökü (RMSEA) 0,14; Tucker-Lewis indeksi (TLI) değeri 0,95, model iyilik uyum indeksi (GFI) 0,97 ve karşılaştırmalı uyum indeks (CFI) değeri 0,97 olarak bulunmuştur. Sonuçlarda görüldüğü gibi ölçek iyi uyum değerlerini sağlamaktadır.

Anketin dördüncü bölümünde İş Gören Sesliliği Ölçeği olarak Van vd. (1998) tarafından geliştirilen 6 maddeden ve tek boyuttan oluşan ölçek kullanılmıştır. Araştırma ölçeğinin sunulan uyum indeksleri incelendiğinde: Ki-kare istatistiğinin serbestlik derecelerine oranı ( $\chi 2 / s d)$ 2,144; yaklaşık hataların ortalama karekökü (RMSEA) 0,088; Tucker-Lewis indeksi (TLI) değeri 0,97, model iyilik uyum indeksi (GFI) 0,97 ve karşılaştırmalı uyum indeks (CFI) değeri ise 0,99 olarak bulunmuştur. Bu bağlamda görüldüğü üzere ölçek iyi uyum değerlerini sağlamaktadır ve iyi uyum göstermektedir. Bu bölümlerde yer alan ölçekler 5'li Likert ölçeğine göre hazırlanmış olup 1=Kesinlikle katılmıyorum, 2=Katılmıyorum, 3=Kararsızım, 4=Katılıyorum, 5=Kesinlikle katılıyorum şeklinde derecelendirilmiş ve ölçümlenmiştir. Bu bağlamda ankette araştırma modelindeki değişkenlere yönelik literatürde güvenilirliği onaylanmış ölçekler yer almaktadir. 


\section{Veri Analizi ve Bulgular}

Araştırma kapsamında Van ilinde faaliyet gösteren otellerde çalışanların çeşitli demografik değişkenlere ilişkin özelliklere göre dağılım bulguları frekans analizi yöntemi ile hesaplanmıştır. Verilerin analizi sonucunda elde edilen bulgular tablo 1'de de görüldügü üzere sunulmuştur.

Tablo 1. Katılımcıların demografik özellikleri

\begin{tabular}{|c|c|c|c|}
\hline & & Frekans & Yüzde (\%) \\
\hline \multirow[t]{2}{*}{ Cinsiyet } & Kadın & 37 & 25,0 \\
\hline & Erkek & 111 & 75,0 \\
\hline \multirow{4}{*}{ Yaş } & $18-25$ & 45 & 30,4 \\
\hline & $26-35$ & 74 & 50,0 \\
\hline & $36-45$ & 26 & 17,6 \\
\hline & $46-55$ & 3 & 2,0 \\
\hline \multirow[t]{5}{*}{ Ĕ̆itim Düzeyi } & İlköğretim & 10 & 6,8 \\
\hline & Ortaöğretim & 31 & 20,9 \\
\hline & Lise & 62 & 41,9 \\
\hline & Ön Lisans & 29 & 19,6 \\
\hline & Lisans & 16 & 10,8 \\
\hline \multirow{6}{*}{$\begin{array}{l}\text { İsletmedeki Konu- } \\
\text { munuz }\end{array}$} & Yönetici & 8 & 5,4 \\
\hline & Ön Büro Personeli & 26 & 17,6 \\
\hline & Mutfak Personeli & 25 & 16,9 \\
\hline & $\begin{array}{l}\text { Yiyecek-İçecek Departmanı Per- } \\
\text { soneli }\end{array}$ & 36 & 24,3 \\
\hline & Kat Hizmetleri Personeli & 29 & 19,6 \\
\hline & Diğer Personel & 24 & 16,2 \\
\hline \multirow{4}{*}{$\begin{array}{l}\text { Oteliniz Kaç Yıl- } \\
\text { dızlı }\end{array}$} & İki Yıldızlı & 3 & 2,0 \\
\hline & Üç Yıldızlı & 36 & 24,3 \\
\hline & Dört Yıldızlı & 23 & 15,5 \\
\hline & Beş Yildızlı & 86 & 58,1 \\
\hline \multirow{4}{*}{$\begin{array}{l}\text { Turizm Sektöründe } \\
\text { Çalışma Süreniz }\end{array}$} & 1 yıldan az & 33 & 22,3 \\
\hline & $1-4$ yıl arası & 65 & 43,9 \\
\hline & $5-9$ yıl arası & 42 & 28,4 \\
\hline & 10 yıl ve üzeri & 8 & 5,4 \\
\hline
\end{tabular}

Araştırmanın katılımcıları olan otel çalışanlarının \%25'i kadın, \%75'i erkektir. Çalışanların yaş dağılımları incelendiğinde \%50 ile en fazla 26-35 yaş arasında olduğu görülmektedir. Eğitim düzeyi dağılımında en yüksek olan oranlar ile katılımcıların $\% 41,9^{\prime} u$ lise, $\% 20,9^{\prime} u$ ortaöğretim ve \%19,6'sının ön lisans mezunu olduğu görülmektedir. Otel çalışanlarının \%24,3'ü Yiyecek-İçecek Departmanı Personeli, \%19,6's1 Kat Hizmetleri 
Personeli, \%17,6'sı Ön Büro Personeli, \%16,9'u Mutfak Personeli, \%16,2'si Diğer Personel ve \%5,4'ü Yönetici olarak çalışmaktadır. Katılımcıların çalıştıkları otele ilişkin bulgular incelendiğinde en fazla \%58,1 ile beş yıldızlı olduğu görülmektedir. Katılımcıların turizm sektöründe çalışma sürelerine ilişkin bulgulara göre, \%43,9'u 1-4 yıl arası, \%28,4'ü 5-9 yıl arası, $\% 22,3$ 'ü 1 yıldan az ve \%5,4'ü 10 yıl ve üzeri şeklinde olduğu söylenebilir.

Araştırma kapsamındaki ölçeklerin veri analizi yapılmadan önce Normallik Testi uygulanmıştır. Kolgomorov Smirnov ve Shapiro Wilk testleri sonucunda elde edilen bulgulara göre önermelerin normal dağılım göstermedikleri tespit edilmiştir. Buradan hareketle veri analizi için istatistiki analiz yöntemlerinden parametrik olmayan yöntemlerin kullanılmasına karar verilmiştir. Çalışmada yer alan araştırma modeli yapısal eşitlik modellemesi yönteminden PLS-SEM (Kısmi En Küçük Kareler) yöntemi ile analiz edilmiştir. Bu analiz yöntemi Smart PLS 3 paket programı kullanılarak test edilmiştir (Ringle, vd. 2005). PLS ölçülen modelin değişkeninin ölçümünde kullanılan ölçeğin güvenilirlik ve geçerliliğinin test edilip modeldeki değişkenler arasındaki ilişkinin derecesi ve anlamlılık düzeyi eş zamanlı olarak değerlendirilmektedir. Araştırma modelinin karmaşıklığından kaynaklı olarak modelde yer alan ana faktörler ikinci düzey faktörken alt faktörler birinci düzey faktör olarak oluşturularak analiz edilmiştir (Hair Hult, Ringle, 2014).

Tablo 2. Araştırma modeli güvenirlikleri

\begin{tabular}{llll}
\hline & $\begin{array}{l}\text { Birlessik Güve- } \\
\text { nilirlik }\end{array}$ & Cronbach's Alpha & AVE \\
\hline Öz yeterlilik & 0,93 & 0,91 & 0,71 \\
Umut & 0,90 & 0,87 & 0,61 \\
Psikolojik Dayanıklılık & 0,90 & 0,87 & 0,62 \\
İyimserlik & 0,83 & 0,72 & 0,56 \\
Alglanan Stres & 0,92 & 0,90 & 0,68 \\
Çalışan Sesliliği & 0,92 & 0,90 & 0,68 \\
\hline
\end{tabular}

PLS analizi sonucuna göre her bir ifadenin Bileşik Güvenilirlik ve Cronbach Alpha değerinin genel kabul görmüş değer olan 0,70 ya da üzerinde olması verinin içsel tutarlılığını sağlamaktadır (Hair vd., 2009). Bu bağlamda test edilen modelin güvenilirlik bulguları Tablo 2' de gösterilmektedir. Analiz sonucunda model için güvenilirlik ve geçerlilik değerleri 
genel kabul görmüş değerin üstünde çıkmıştır (Nunnally, 1978). Aynı zamanda Açıklanan Ortalama Varyans (Average Variance Extracted) değeri hesaplanmış ve bu değer Fornell ve Larcker (1981)'in önerdiği 0.50'in üzerindedir. Dolayısıyla bu bulgular dikkate alındığında araştırma modelinin ve ölçeklerin güvenilirlik ve geçerlilik kriterlerini sağladığ 1 ifade edilmektedir.

Çalışmada yakınsaklık geçerliliği (convergent validity) Smart PLS yöntemi ile önermelerin ayrı ayrı faktör yüklemeleri yapılarak analiz edilmiştir. Tüm faktör yüklemelerinin bu doğrultuda ankette yer alan önermelerin ilgili faktörlere yüklendiği tespit edilmiştir. Dolayısıyla çalışmada kullanılan ölçeklerin yakınsaklık geçerliliği onaylanmıştır.

Tablo 3. Ayırt edicilik geçerliliği için heterotrait-monotrait (htmt) değerleri

\begin{tabular}{lcccccc}
\hline & $\ddot{O Z Z Y}$ & UMT & DYNK & IYMS & ALSTR & SES \\
\hline ÖZY & & & & & & \\
UMT & 0,88 & & & & & \\
DYNK & 0,38 & 0,50 & & & & \\
IYMS & 0,46 & 0,58 & 0,82 & & & \\
ALSTR & 0,14 & 0,17 & 0,35 & 0,36 & & \\
SES & 0,48 & 0,38 & 0,32 & 0,28 & 0,10 &
\end{tabular}

Not: PS: Psikolojik Sermaye, ÖZY: Özyeterlilik, UMT: Umut, DYNK: Dayanıklilik, IYMS: İyimserlik, ALSTR: Algılanan Stres, SES: Çalışan Sesliliği

Araştırma modeli değişkenlerinin her birinin farklı bir kavramı ölçtügünün tespit edilebilmesi için ayırt edicilik geçerliliği (discriminant validity) Heterotrait-Monotrait (HTMT) oranı aracılığıyla hesaplanmıştır. Ayırt edicilik geçerliliğinin HTMT oranları matriks formatında Tablo 3 'te verilmiş ve HTMT oranı değerleri 0,90'ın altında olduğundan ayırt edicilik geçerliliği onaylanmıştır.Değişkenlerin birbirlerinden farklı oldukları sonucuna varılmıştır. Ayrım geçerliliğini belirlemek için AVE değerlerinin karekökü hesaplanmıştır (Fornell ve Larcker, 1981). AVE değerinin karekökü, yapıdaki diğer tüm örtük değişkenlerle olan korelasyonundan daha büyük olmalıdır (Hair vd., 2019). Araştırma modelinde yer alan değişkenler arasındaki korelasyon katsayıları ve anlamlılık düzeyleri diğer bir ifade ile değişkenlerin birbirleri ile kendi aralarında ilişkili olup olmadığını ve ilişkinin yönünü araştırmak için yapılan korelasyon testi sonuçları incelenmiş ve değişkenler arası korelasyonlar rapor edilmiştir. 


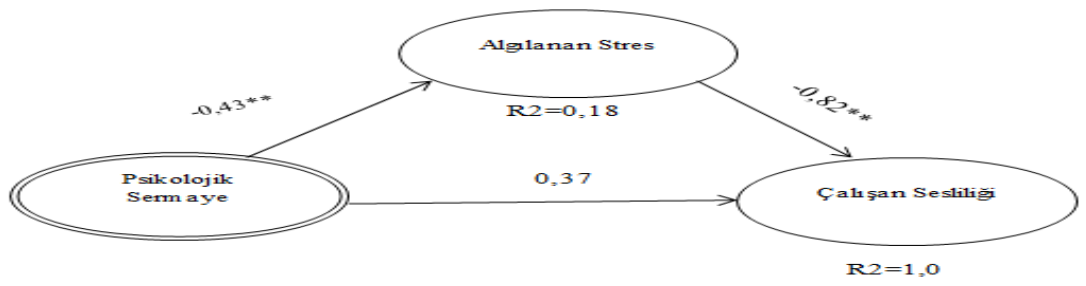

$* \mathrm{P}<0,05, * * \mathrm{p}<0,01$

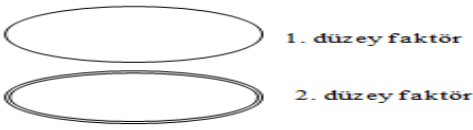

Şekil 2. Yapısal model ilişkilerinin test sonuçları

Yapısal model sonuçlarına ilişkin bilgiler Şekil 2'de verilmiştir. Buradan hareketle değişkenler arasındaki bağlantıların Beta $(\beta)$ katsayıları ve R2 değeri yer almaktadır. Yapısal model sonuçlarına göre psikolojik sermaye algılanan stresi negatif yönlü ve anlamlı şekilde etkilemektedir $(\beta=$ $-0,43 ; \mathrm{p}<0.01$ ). Psikolojik sermayenin algılanan stresteki değişimin \% 18 'ini $(\mathrm{R} 2=0,18)$ açıkladığı görülmektedir. $\mathrm{f} 2$ değeri ise orta düzeyde etki olduğunu göstermektedir (f2=0,23). Öncelikle psikolojik sermayenin çal1şan sesliliği üzerindeki etkisi aracı değişken olan algılanan stres olmadan incelenmiş ve sonuç anlamlı olarak tespit edilmiştir. Psikolojik sermaye çalışan sesliliğini pozitif yönlü ve anlamlı şekilde etkilemektedir $(\beta=0,44$; $\mathrm{p}<0.01$ ). Psikolojik sermayenin çalışan sesliliğindeki değişimin \% 19 (R2= $0,19)$ açıkladığ görülmektedir. f2 değeri ise orta düzeyde etki olduğunu göstermektedir ( $\mathrm{f} 2=0,03)$. Algılanan stres çalışan sesliliğini negatif yönlü ve anlamlı şekilde etkilemektedir $(\beta=-0,82 ; p<0.01)$. Algılanan stres iş gören sesliliğindeki değişimin \% $100(\mathrm{R} 2=1,00)$ açıkladığ1 görülmektedir. f2 değeri ise yüksek düzeyde etki olduğunu göstermektedir ( $\mathrm{f} 2=0,74)$. Bu bulgulardan elde edilen veriler doğrultusunda Hipotez 1, Hipotez 2 ve Hipotez 3 desteklenmiştir. Çalışma kapsamında, araştırma modelinde yer alan aracı değişken arasındaki etkiyi test etmek amaçlanmıştır. PLS-SEM analizi sonucunda algılanan stres, psikolojik sermayenin çalışan sesliliği üzerindeki etkisinde aracı rolü oynamaktadır hipotezi Baron ve Kenny (1986) tarafından geliştirilen aracılık yöntemi ile test edilmiştir. Araştırma bulgularına göre algılanan stres psikolojik sermaye ile iş gören sesliliği arasındaki etkiye aracılık etmediği görülmektedir. 


\section{Sonuç ve Tartışma}

Karar verme, örgütsel yaşamın temel taşıdır. Her organizasyonda her gün strateji, personel, operasyon, finans ve pazarlama konularında sayısız karar alınmaktadır. Seslilik ya da sessiz kalmak, her çalışan, her yönetici için günde en az bir defa verilen bir karardır (Morrison ve Milliken, 2003). Bu bağlamda çalışanı seslilik davranışına yönelten pozitif psikolojik kapasiteler ve sesliliği etkileyen stres gibi olumsuz psikolojik durumlar iyi anlaşılmalıdır.

Yazında psikolojik sermaye ile iş stresi arasında negatif ilişkiler bulunduğunu ortaya koyan çalışmalar mevcuttur. Bu çalışmalar stresin doğal olarak negatif gibi gözükmesine rağmen, makul bir miktar stresin pozitif psikolojik gelişimine katkı sağlayabileceği durumlara işaret etmektedir. Makul miktarda stres, bir çalışanı daha etkili, umutlu, esnek ve iyimser yapabilir, özellikle de başarı genellikle böyle bir stresten sonra gelebilir (Haq 2014; Aderibigbe, 2019). Ancak stresin fazla olduğu ve kontrol altına alınmadığı takdirde çalışanlarını olumsuz etkilemektedir. Çalışanların kaygı yaşamalarına, verimli ve etkin çalışmalarına ve işlerini gereği gibi yerine getirememelerine neden olmaktadır.

Çalışma kapsamında Van ilinde faaliyet gösteren otellerde çalışanların \%25'i kadın, ve \%75'i erkekten oluşmaktadır. Çalışanların \%50 ile en fazla 26-35 yaş aralığında ve \%41,9'unun lise mezunu olduğu tespit edilmiştir. Otel çalışanlarının \%24,3' ü Yiyecek-İçecek Departmanı Personeli, \%19,6's1 Kat Hizmetleri Personeli, \%17,6'sı Ön Büro Personeli, \%16,9'u Mutfak Personeli, \%16,2'si Diğer Personel ve \%5,4'ü Yönetici şeklinde yer almaktadır. \%58,1 ile çalışanların daha çok beş yıldızlı otelde çalıştıkları görülmektedir. Otel çalışanlarının \%43,9'u 1-4 yıl arası turizm sektöründe çalışmaktadir.

Araştırmada belirlenen amaçları gerçekleştirebilmek ve oluşturulan hipotezleri test edebilmek amacıyla Van ilinde yapılan araştırmada elde edilen bulgular ışığında "Hipotez 1: Psikolojik sermaye algılanan stresi negatif yönlü ve anlamlı olarak etkiler" hipotezi için araştırma modeli sonuçları incelendiğinde psikolojik sermaye algılanan stresi negatif yönlü ve anlamlı etkilemektedir $(\beta=-0,43 ; \mathrm{p}<0.01)$. "Hipotez 2: Psikolojik sermaye çalışan sesliliğini pozitif yönlü ve anlamlı olarak etkiler" hipotezi için model bulgularında psikolojik sermayenin çalışan sesliliğini pozitif yönlü ve 
anlamlı etkilediği görülmektedir $(\beta=0,44 ; \mathrm{p}<0.01)$. "Hipotez 3: Algılanan stres çalışan sesliliğini negatif yönlü ve anlamlı olarak etkiler" hipotezinden yola çıarak algılanan stresin çalışan sesliliğini negatif etkilediği bulgusuna erişilmektedir $(\beta=-0,82 ; p<0.01)$. Dolayısıyla bu bulgulardan hareketle Hipotez 1, Hipotez 2 ve Hipotez 3 'ün desteklendiği tespit edilmiştir. "Hipotez 4: Algılanan stres, psikolojik sermayenin çalışan sesliliği üzerindeki etkisinde aracı rolü oynar" hipotezi için aracılık testi yapılmıştır. Elde edilen analiz bulgularına göre algılanan stresin psikolojik sermaye ile iş gören sesliliği arasındaki etkiye aracılık etmediği tespit edilmiştir. Bu bulgulardan hareketle Hipotez 4 reddedilmiştir.

Genel olarak sonuçlar yorumlandığında, psikolojik sermayesi yüksek olan çalışanların stres düzeylerinin düşük olması beklenmektedir. Aynı zamanda psikolojik sermaye çalışan sesliliğini etkilerken psikolojik olarak kendilerini iyi hisseden çalışanlar işlerin de motive olarak çalışan sesliliğini de pozitif olarak etkilemektedir. Çalışanların yaşadıkları stres onların fikirlerini iletme, önerilerde bulunma vb durumlarını olumsuz etkilemektedir. Ayrıca stres çalışanların kaygı düzeylerini de artırmaktadır. Yani stres çalışan sesliliği olumsuz etkilemektedir. Araştırma modelinde alg1lanan stres aracı olarak psikolojik sermayenin iş gören sesliliği üzerindeki etkisinde anlamsız çıkması da üzerinde durulması gereken önemli bir sonuçtur. Başka bir ifade ile stres psikolojik sermayenin etkili olmasında çalışanın kendi düşüncelerini ifade etmesi yani çalışan sesliliğini olmasında fayda sağladığı düşünülmemektedir. Araştırma modeli çerçevesinde elde edilen bulguların literatüre fayda sağlayacağı düşünülmektedir. Araştırmanın gerçekleştirilmesindeki kısıtlar ve belirli bir sektörün olması durumları da çalışmanın farklı illerde farklı sektör çalışanları üzerinde yapılarak kıyaslanması, farklı değişken ve modellerle incelenmesi ve daha geniş bir evrende uygulanması araştırmaya konulması temel önerilerimizdir. 
EXTENDED ABSTRACT

\title{
The Mediating Role of Perceived Stress in the Relationship Between Psychological Capital and Employee Voice: A Research in the Service Sector
}

\author{
Sümeyra Ceyhan - Olcay Okun \\ Bingöl University- National Defense Department
}

Positive psychology, which has been in pursuit of knowledge that makes life meaningful and more fruitfull since the 2000s, has become the focus of attention of researchers and has turned into a positive psychology trend. Psychological capital, which is the reflection of the positive psychology movement on organizational behavior, is defined as studies and practices on the strengths of positive psychological human capacities in order to increase employee performance in business life (Luthans et al., 2006). Today, the well-being or happiness of the individual in general, and the employee in particular, has spread to all parts of life and working life in terms of positive or negative returns to organizations and employee productivity. Employee voice, which is addressed in terms of how employees can do their jobs better and how their work environment can be better, is a phenomenon that shows the tendency of employees to express their feelings and thoughts. Perceived stress is a psychological state that results from work-related factors that deviate the individual from their normal functions and change their physical or psychological behaviors.

In the literature, it has been determined that the interaction of psychological capital with the concepts of employee voice and stress has not been examined and there is a lack of knowledge in this context for field researchers. In the study, the effect of psychological capital on employee voice and perceived stress was examined. With the study, it is aimed to fill the gap in the literature by revealing the effects between the phenomena and to contribute to the management literature. All hotels operating in the province of Van (two 5 star, four 4 star, six 3 star and 2 apart hotels) were included in the research. By reaching the entire universe, the questionnaire used as a measurement tool between February and April 2018 was app- 
lied to a total of 247 personnel working in hotel businesses, and 148 questionnaires were found worthy of evaluation and analyzed. In the study, Luthans et al. (2007a) 24-item Positive Psychological Capital Scale The psychological capital scale was translated into Turkish by Çetin and Basım (2012), Van Dyne et al. (1998) Employee Vocality Scale, consisting of 6 items and one dimension, and Cohen, et al. The Work Stress Scale developed by (1983) was used. In the analysis of the data obtained in the study, the SPSS program and the PLS-SEM (Partial Least Squares) method from the structural equation modeling method of the research model were used. This analysis method has been tested using the Smart PLS 3 package program (Ringle, et al. 2005). According to the results of the PLS analysis, the composite reliability and cronbach alpha values of each statement were above the generally accepted value. It is stated that the research model and the scales, whose Average Variance Extracted value is calculated, meet the reliability and validity criteria. In the study, the convergent validity of the propositions was analyzed with the Smart PLS method by making factor loadings separately, and it was determined that all factor loadings were loaded on the relevant factors, and the convergent validity of the scales was confirmed. In order to determine that each of the research model variables measured a different concept, the discriminant validity Heterotrait-Monotrait (HTMT) was calculated and approved. The results of the correlation test for the correlation coefficients and significance levels between the variables in the research model were examined and the correlations between the variables were reported.

According to the structural model results, psychological capital affects perceived stress negatively and significantly $(\beta=-0.43 ; p<0.01)$. It is seen that psychological capital explains $18 \%(\mathrm{R} 2=0.18)$ of the change in perceived stress. The $\mathrm{f} 2$ value indicates a moderate effect $(\mathrm{f} 2=0.23)$. First of all, the effect of psychological capital on employee voice was examined without the mediating variable perceived stress, and the result was found to be significant. Psychological capital positively and significantly affects employee voice $(\beta=0.44 ; p<0.01)$. It is seen that the change in employee voice of psychological capital explains $19 \%(\mathrm{R} 2=0.19)$. The $\mathrm{f} 2$ value indicates a moderate effect $(\mathrm{f} 2=0.03)$. Perceived stress affects employee voice negatively and significantly $(\beta=-0.82 ; p<0.01)$. It is seen that the perceived stress explains the change in employee voice by $100 \%(\mathrm{R} 2=1.00)$. The $\mathrm{f} 2$ 
value indicates a high level of effect ( $\mathrm{f} 2=0.74$ ). In line with the data obtained from these findings, Hypothesis 1, Hypothesis 2 and Hypothesis 3 were supported. Within the scope of the study, it was aimed to test the effect between the mediator variable in the research model. As a result of PLS-SEM analysis, the hypothesis that perceived stress plays a mediating role in the effect of psychological capital on employee voice was tested with the mediation method developed by Baron and Kenny (1986). According to the research findings, it is seen that perceived stress does not mediate the effect between psychological capital and employee voice. Based on these findings, Hypothesis 4 was rejected.

When the results of the research are interpreted, it is expected that the stress levels of the employees with high psychological capital will be low. At the same time, while psychological capital affects employee voice, employees who feel good psychologically also positively affect the motivated voice of their work. The stress experienced by the employees negatively affects their ability to convey their ideas, make suggestions, etc. In addition, stress increases the anxiety levels of employees. In other words, stress negatively affects employee voice. It is an important result that should be emphasized that the effect of psychological capital, as a perceived stress tool, on employee voice is meaningless in the research model. In other words, it is not thought that it is beneficial for the employee to express their own thoughts, that is, to have employee voice, in the effectiveness of stress psychological capital. It is thought that the findings obtained within the framework of the research model will benefit the literature. The limitations in the realization of the research and the presence of a certain sector are also our basic suggestions to compare the study by doing it on different sector employees in different provinces, to examine it with different variables and models, and to apply it in a wider universe.

\section{Kaynakça / References}

Adams, R. D., Meyers, S. A. ve Beidas, R. S., (2016). The relationship between financial strain, perceived stress, psychological symptoms, and academic and social integration in undergraduate students. Journal of American College Health, DOI: 10.1080/07448481.2016.1154559. 
Aderibigbe, J. K. ve Mjoli, T., (2019). “Q. african journal of business \& economic research", 14(1), 85-111. 27p. DOI: 10.31920/17504562/2019/v14n1a5

Adelman, K., (2012). Promoting employee voice and upward communication in health care: The CEO's Influence. J Healthc Manag., 57(2), 133-47.

Akçadağ, S. ve Özdemir, E. (2005). İnsan kaynakları kapsamında 4 ve 5 yıldızlı otel işletmelerinde iş tatmini: İstanbul'da yapılan ampirik bir çalışma, Kocaeli Üniversitesi Sosyal Bilimler Enstitüsü Dergisi, 10, 167-193.

Allen, J.,Yoerger, Lehmann-Willenbrock, N. ve Jones, J., (2015). Would you please stop that!?: The relationship between counter productive meeting behaviors, employee voice and trust. Journal of Management Development, 34(10), 1272-1287.

Avey, J., Wernsing, T. ve Luthans, F., (2008). Can positive employees help positive organizational change? Impact of psychological capital and emotions on relevant attitudes and behaviors. The Journal of Applied Behavioral Science, 44(1), 48- 70.

Bandura, A., (1997). Self-efficacy: The exercise of control. New York, NY: Freeman.

Baron, R. M. ve Kenny, A. D., (1986). The moderator-mediator variable distinction in social psychological research: conceptual, strategic and statistical considerations. Journal of Personality And Social Psychology, 51(6), 1173-1182.

Beer, M. ve Eisenstat, R. (2000). The silent killers of strategy implementation and learning. Sloan Management Review, 41, 29-40.

Burris, E. R., Rockmann, K. W. ve Kimmons, Y. S., (2017). The value of voice to managers: employee identification and the content of voice. Academy of Management Journal, 60(6), 2099-2125.

Cohen, S., Kamarck, T. ve Robin, M., (1983). A global measure of perceived stress. Journal of Health and Social Behavior, 24(4), 385-396.

Çetin, F., ve Basım, H. N., (2012). Örgütsel psikolojik sermaye: Bir ölçek uyarlama çalışması. Amme İdaresi Dergisi, 45(1), 121-137.

Detert, J. R., ve Burris, E. R., (2007). Leadership behavior and employee voice: Is the door really open?. Academy of Management Journal, 50, 869-884.

Erkuş, A., ve Findikll, M. A. (2013). A study on the effect of psychological capital on job satisfaction, job performance and intention to quit. Journal of Istanbul University Faculty of Business Administration, 4(22), 302-318. 
Farndale, E., Van Ruten, j., Hope-Hailey, V. ve Kelliher, C., (2011). The influence of perceived employee voice on organizational commitment: an exchange perspective. Human Resource Management, 50(1), 113-129, DOI: 10.1002/hrm.20404.

Gunawardana, S. J., (2014). Reframing employee voice: A case study in sri lanka's export processing zones. Work, Employment and Society, 28(3), $452-468$.

Hair, J. F., Black W. C., Babin B. J. ve Anderson, R.E. (2009). Multivariate data analysis. Printice Hall

Hair, J. F., Risher, J. J., Sarstedt, M. and Ringle, C. M. (2019). When to use and how to report the results of PLS-SEM. European Business Review, 31(1), 2-24.

Hair, JR, J. F., Hult, G. T. M., Ringle, C. M. ve Sarstedt, M., (2014). A primer on partial least squares structural equation modeling (PLS-SEM). Sage Publications, Thous and Oaks, California, 307p.

Haskins, M. E., ve Freeman R. E., (2015). What managers should never want to hear: silence. Management Decision, 53(6), 1300 - 1311.

Haq, I. U., (2014). Work place ostracism and job outcomes: moderating effects of psychological capital. International Conference on Management, Knowledge and Learning, 25-27.

Henseler, J., Ringle, C. M. ve Sinkovics, R. R., (2009). The use of partial least squares path modeling in international marketing. in $r$. r. sinkovics $\mathcal{E}$ p.n. ghauri (Eds.), Advances in International Marketing. Emerald, Bingley, 277-320.

Hobfoll, S. E., (1989). Conservation of Resources: A new attempt at conceptualizing stress. American psychologist American psychological association, 44(3), 513-525.

Kell, Harrison J., Robbins, Steven B., ve Su, R. (2018). ETS Research report series, (EJ1202767).

Küçükusta, D., (2007). Konaklama işletmelerinde iş-yaşam dengesinin çalışma yaşamı kalitesi üzerindeki etkisi. Doktora tezi, Dokuz Eylül Üniversitesi, Sosyal Bilimler Enstitüsü, İzmir.

Li, C., Liang, J., ve Farh, J. L. (2018). Speaking up when water is murky: An uncertainty-based model linking perceived organizational politics to employee voice. Journal of Management, 46(3), 443-469. DOI: $10.1177 / 0149206318798025$. 
Luthans, F., (2002). The need for and meaning of positive organizational behavior. Journal of Organizational Behavior, 23(6), 695-706.

Luthans, F., Youssef, C. M., ve Avolio, B. J., (2007a). Psychological capital: developing the human competitive edge. New York: Oxford UniversityPress.

Luthans, F., Avolio, B., Avey, J. B., ve Norman, S. M. (2007b). Psychological capital: measurement and relationship with performance and job satisfaction. Personnel Psychology, 60, 541-572.

Luthans, F. (2012). Psychological capital: Implications for hrd, retrospective analysis, and future directions. Human Resource Development Quarterly, 23(1), 1-8. doi: 10.1002hrdq. 21119.

Mensah, j., ve Amponsah-Tawiah, K., (2016). Mitigating occupational stress: The role of psychological capital. Journal of work place behavioral health. 31(4),189-203. DOI: 10.1080/15555240.2016.1198701.

Met, Ö. ve Erdem, B. (2006). Konaklama işletmelerinde konaklama işletmelerinde verimliliğin ölçülmesi ve verimliliği verimliliğin ölçülmesi ve verimliliği etkileyen etkenlerin analizi etkileyen etkenlerin analizi. Ticaret ve Turizm Eğitim Fakültesi Dergisi, 2, 53-73.

Milliken, F J, Morrison, E W. ve Hewlin P (2003). An exploratory study of employee silence: issues that employees don't communicate upward and why. Journal of Management Studies, 40, 1453-1476.

Morrison, E. W. (2011). Employee voice behavior: integration and directions for future research. The Academy of Management Annals, 5(1), 373412.

Morrison, E. W. ve Milliken, F. J. (2003). Speaking up, remaining silent: The dynamics of voice and silence in organizations. Journal of Management Studies, 40(6), 1353-1358.

Okun, O., (2017). Psikolojik sermayenin iş gören sesliliğine etkisinde iyi olma halinin araci rolü. Doktora tezi, Hasan Kalyoncu Üniversitesi, Sosyal Bilimler Enstitüsü, İşletme Anabilim Dalı, Gaziantep.

Ringle, C. M., Wende, S. ve Will, A., (2005). Smart PLS2.0. University of Hamburg, Hamburg, Germany.

Sameer, Y. M., Mohamad S. ve Mohamed, A. A. (2019). Antecedents of psychological capital: the role of work design. Journal of Economics $\mathcal{E} M a$ nagement, 35(1), 124-149. 
Santiago, P. H. R., Roberts, R., Smithers, L. G. ve Jamieson, L. (2019). Stress beyond coping? A rasch analysis of the perceived stress scale (PSS-14) in an aboriginal population. PlusPone, 14(5), 1-24. DOI: 10.1371/journal.pone.0216333.

Seligman, M. E. P. ve Csikszentmihalyi, M. (2000). Positivepsychology: An introduction. American Psychologist, 55(1), 5-14.

Smith, A. (2005). An inquiry into the nature and causes of the wealth of nations. Hazleton, PA: Electronic Classics Series. (Original work published 1776).

Snyder, C. R. (2000). Hand book of hope. San Diego: AcademicPress.

Şahin, Ç. (2013). Impact of teachers' perceptions of organizational support, management openness and personality traits on voice. Educational Research and Reviews, 8(18), 1-10.

Turunç, Ö. (2015). İşs stresi - kaytarma ilişkisinde liderin rolü: Turizm sektöründe bir araştırma. Uluslararası İktisadi ve İdari Bilimler Dergisi, 1(2), 142-159.

Vakola, M. ve Bouradas, D. (2005). Antecedents and consequences of organisational silence: An empirical investigation. Employee Relations, $27(4 / 5), 441-458$.

Van Dyne, L. ve Lepine, J. A. (1998). Helping and voice extra-role behaviour: Evidence of constructand predictive validity. The Academy of Management Journal, 41(1), 108- 119.

\section{Kaynakça Bilgisi / Citation Information}

Ceyhan, S. ve Okun, O. (2021). Psikolojik sermaye ile çalışan sesliliği arasindaki ilişkide algılanan stresin aracılık rolü: Hizmet sektöründe bir araştırma.OPUS-Uluslararası Toplum Araştırmaları Dergisi, 18(39), 255-276. DOI: 10.26466/opus.835768. 